\title{
Semipresidencialismo e Hiperpresidencialismo en la Reforma Constitucional Argentina de 1994
}

\author{
Semipresidencialismo e Hiperpresidencialismo na Reforma Constitucional \\ de 1994 na Argentina
}

Semipresidentialism and Hyperpresidentialism in Argentina's 1994
Constitutional Reform

Marcelo Alberto López Alfonsín

Resumen: La reforma constitucional de 1994 disparó importantes consecuencias en el sistema político argentino. En trabajos anteriores ${ }^{1}$ analizamos su proceso de gestación, los objetivos que la guiaron y su cumplimiento en la práctica político-institucional. Concluimos que la puesta en práctica de la reforma, por medio de la legislación reglamentaria y la práctica política, supone una contrareforma al espíritu constituyente. Evaluaremos el funcionamiento del Jefe de Gabinete de Ministros y los Decretos de Necesidad y Urgencia. Expondremos cómo la Reforma, que incluye mecanismos del semipresidencialismo y fuertes controles al Poder Ejecutivo, fue utilizado políticamente para la reglamentación de un hiperpresidencialismo.

Palabras clave: Semipresidencialismo. Hiperpresidencialismo. Reforma Constitucional Argentina de 1994.

\begin{abstract}
Ariela Schnitmann
Resumo: A reforma constitucional de 1994 desencadeou importantes consequências no sistema político argentino. Nos trabalhos anteriores ${ }^{1}$ analisamos seu processo de gestação, os objetivos que a guiaram e a aplicação na prática político-institucional. Concluímos que a implantação da reforma, por meio da legislação regulamentar e da prática política fez presumir uma contrarreforma ao espírito do constituinte. Neste artigo avaliaremos o funcionamento do Chefe de Gabinete de Ministros e os Decretos de Necessidade e Urgência e demonstraremos como a reforma, que inclui mecanismos de semipresidencialismo e de controles fortes do Poder Executivo, foi politicamente utilizada para regulamentar um hiperpresidencialismo.

Palavras-chave: Semipresidencialismo. Hiperpresidencialismo. Reforma Constitucional Argentina de 1994.
\end{abstract}

\begin{abstract}
The 1994 constitutional reform triggered important implications on the Argentine political system. In previous work ${ }^{1}$ we analysed its development process, objectives which guided it and the compliance with its political-institutional practice. It is concluded that the implementation of the reform, through regulatory legislation and political practice, represents a counter-reform to the constituent spirit. We shall assess the chief of the cabinet of ministers' performance and the Necessity and Urgency Decree.We will show how the reform, which includes mechanisms of semipresidentialism and strong controls of the Executive Branch was politically used for regulation of a hyperpresidentialism.
\end{abstract}

Keywords: Semipresidentialism. Hyperpresidentialism. The Argentinian Constitutional Reform of 1994.

Artigo recebido em 14 mar. 2016 e aprovado em 28 abr. 2016.

1 Ambos se encuentran editados por EUDEBA. Ambos se encontram editados por EUDEBA. Both published by EUDEBA. 


\section{Introducción}

Según Grossi y Gritti (1989) hasta 1983 la UCR y el PJ se enfrentaban electoralmente no tanto para definir quién sería gobierno sino más bien para establecer definitivamente qué tipo de régimen político prevalecería. Varios autores han estudiado la difícil convivencia de estas dos concepciones divergentes de la democracia, la representativa y la plebiscitaria o delegativa, y han mostrado cómo la ausencia de un acuerdo que sentara las bases de una comunidad política estable condujo a la imposibilidad fáctica de la alternancia en el poder. (DE RIZ Y ADROGUÉ 1990; ALFONSÍN 2005; O'DONNELL 1972; KVATERNIK 1994).

Rossati (1995) y Garcia Lema (1995) explican cómo, en busca de un compromiso democrático que rompa con esta tradición, desde 1986 la idea de la reforma constitucional fue ampliamente discutida en el seno de estos partidos, en la academia, y en la sociedad.

El presente trabajo se orienta al análisis de la Reforma Constitucional de 1994, desde los procesos y objetivos políticos que le dieron origen hasta las consecuencias de la misma sobre nuestro régimen político y sistema partidario.

Estudiaremos algunos aspectos del proceso de su gestación intentando responder al discurso dogmático instalado en la opinión pública $\mathrm{y}$ entre algunos intelectuales que aspira a reducir su contenido a un pacto conspirativo para llevar a la reelección al Dr. Carlos Saúl Menem.

Rescataremos al "Pacto de Olivos", firmado por el Dr. Menem en su carácter de Presidente del Partido Justicialista, y el Dr. Raúl Ricardo Alfonsín, como uno de los elementos políticos más significativos en la construcción del consenso constitucional que se venía construyendo ya desde el denominado Consejo para la Consolidación de la Democracia en su primer dictamen (1987), y profundizado en el segundo (1988). ${ }^{2}$

Tal como lo expresara el constituyente García Lema en la Convención Nacional Constituyente, "estos acuerdos han sido gestados durante muchos años, durante los cuales ambos partidos han intercambiado sus respectivos roles. Los estudios para la reforma de la Constitución 151 Convención Nacional Constituyente fueron iniciados cuando el ra-

2 Ambos se encuentran editados por EUDEBA. 
dicalismo era el partido del gobierno y el justicialismo la principal fuerza opositora, y concluyeron en un acuerdo cuando el justicialismo es el partido el gobierno y el radicalismo la principal fuerza opositora. Esta circunstancia de intercambio de los roles ha determinado que exista una profunda comprensión de las dificultades que presenta la realidad, que ha tenido que afrontar esta reforma, y al mismo tiempo las soluciones que han debido elaborarse para resolver estos inconvenientes. Si bien el acuerdo, el consenso, fue alcanzado principalmente por las fuerzas del justicialismo y del radicalismo, no puede desconocerse que otras importantes fuerzas políticas, económicas y sociales han prestado diferentes grados de asentimiento a las reformas propuestas en el Núcleo de Coincidencias Básicas".

La participación pluralista de todos los sectores de la sociedad de la mano del compromiso de garantías entre los protagonistas, hizo posible la readecuación de nuestra carta orgánica a la luz del derecho comparado, agregándole la necesaria atenuación del presidencialismo argentino como requisito indispensable para el afianzamiento de la democracia recuperada en 1983.

A lo largo del estudio demostraremos cómo el espíritu de la Reforma, la atenuación del presidencialismo, plasmado por nuestros constituyentes tanto en su articulado como en la Convención, no solo ha quedado frustrado sino que sufrió una contrareforma de fondo.

Expondremos en este trabajo cómo el texto de la Reforma, que incluye mecanismos del semipresidencialismo y fuertes controles al Poder Ejecutivo, junto a otras innovaciones, orientados a la moderación del presidencialismo, fue utilizado políticamente como puntapié de la reglamentación de uno de los hiperpresidencialismos más agudos que hemos vivido.

No sólo los objetivos reformistas no se cumplieron, sino que se han visto distorsionados y manipulados por los gobiernos que presidieron a la Reforma, en el marco de una decisión política de consolidar un hiperpresidencialismo.

Las nuevas instituciones no solucionaron los problemas por los cuales fueron creados, dado que fueron vaciados de contenido al momento de su implementación. (FLEITAS ORTIZ 1995; MUÑOZ 1995; PAIXAO 1994; SERRAFERO 1994; GALLARDO, Y LÓPEZ 1995; 
BELARDINELLI Y CORTI, 1996, RASPI 1996; CASSAGNE 1994; REGNIEL 2006; PERSELLO 2007; MC ADAM Y SUKUP 2009).

Por su parte, Llanos y Mustapic (2006) evidenciaron un sistema deficitario de pesos y contrapesos, agravado por la adopción unilateral de decisiones. Desde la teoría de la dependencia de la trayectoria podría afirmarse que las reformas, guiadas por una visión representativa de la democracia, no fueron capaces de revertir el peso de una institución informal relacionada con la lógica de poder delegativa, prexistente a la reforma, que tiene profundas raíces históricas en nuestro país. (PIERSON 2004, O’DONNELL 1997).

La legislación y la puesta en marcha de la Reforma reforzaron las características delegativas del sistema político argentino (MECLE Y GUTERMAN 2011; PEREZLIÑAN 2003; OLLIER 2008), en contraposición con la visión republicana de la democracia que le dio origen.

En este trabajo se parte de una primera hipótesis de que la visión representativa de la democracia primó en el proceso de formación de la Reforma y en la Convención Constituyente, mientras que la visión delegativa de la democracia logró imponerse luego de estas.

La segunda hipótesis postula que el espíritu de la Reforma Constitucional no sólo no fue cumplido sino que sufrió una "contrarreforma" por la reglamentación e implementación que le prosiguieron, consolidando una democracia delegativa (O'DONNELL, 1994) y un superpresidencialismo (Mainwaring y Shugart, 2002).

Entendemos el concepto de sistema superpresidencialista dentro de las tipologías de Mainwaring,S. y Shugart,M.S, quienes sostienen que "los sistemas presidencialistas varían en formas importantes, sobre todo en relación con: (1) los poderes constitucionales asignados al presidente y (2) el tipo de partidos y de sistema de partidos".

Esto es, la "fortaleza" de los presidentes descansa sobre dos categorías de poderes presidenciales: poderes partidarios y poderes constitucionales, a saber; atribución de vetar parcial o totalmente proyectos de ley, facultad de emitir decretos-ley, tener iniciativa legislativa y exclusividad de legislar sobre algunos temas.

El presidencialismo argentino cuenta hoy con grandes poderes partidarios, no es casualidad que gran parte de nuestros ex presidentes hayan sido a su vez presidentes de su partido, y enormes facultades. 
La Contrareforma, distorsionando el espíritu de nuestra Carta Maga y manipulando su articulado, ha otorgado a los presidentes argentinos la potestad de vetar parcial o totalmente proyectos de ley, emitir decretos-ley, y de arrogarse para sí facultades propias del Poder Legislativo. Se ha convertido lo que debería ser excepcional en algo ordinario.

Como explicara Guillermo O'Donnell (1994), esta manera de concebir y ejercer el poder, esta lógica que entiende a la política como medio de acumulación de poder y no al poder como medio para hacer política, es uno de las características más sobresalientes de las "Democracia delegativa" en la cual los líderes creen que los ciudadanos les delegan un poder absoluto y que todo control institucional es una injustificada traba.

La Reforma Constitucional venía a sanear la larga tradición delegativa de nuestro país, reforzando no solo la accountability vertical, la cual está implicada a la rendición de cuentas que periódicamente los gobernantes experimentan en las urna, sino incorporando en nuestra Carta Magna la accountability horizontal, que opera mediante una red de poderes relativamente autónomos (es decir, instituciones) que pueden examinar y cuestionar y, de ser necesario, sancionar actos irregulares cometidos durante el desempeño de los cargos públicos.

Los Constituyentes tenían en claro que la representación y la accountability conforman la dimensión republicana de la democracia, sin la cual no existiría una clara distinción entre los intereses públicos y privados de los funcionarios, y avanzaron hacia una "Democracia Representativa" dentro de un sistema presidencialista limitado.

La Contrareforma Constitucional no solo ha re significado la letra constitucional sino que, además, la ha utilizado políticamente para el establecimiento de una "Democracia Delegativa" dentro de un sistema superpresidencialista.

En contraposición con un enfoque netamente institucional que sostiene el best system approach, dejando de lado el contexto en el que se desarrollan las instituciones, este trabajo entiende que no sólo las instituciones tienen un peso relativo, sino que la cultura política y los actores tienen mucha incidencia en el desempeño de éstas (NOHLEN, 2007; O’DONNELL, 1997). 
Según Nohlen (2007)

Frente a posturas netamente institucionalistas y otras de corte más "blando" que colocan en el centro de la causalidad a la cultura política, el enfoque histórico-empírico afirma que si bien las instituciones cuentan, su rol y desempeño dependen de la contingencia política confirmada por una combinación de factores de variada índole.

Hacer foco en el comportamiento y valores de los actores políticos permite ver e intentar explicar la brecha entre el mundo normativo y el desarrollo de la cultura democrática. Por ellos, se realizará un estudio de caso que permita confirmar o no las hipótesis planteadas intentando responder si los objetivos de los constituyentes se cumplieron o no y el porqué de estos resultados.

Como fundamento práctico de esto evaluaremos el funcionamiento de los siguientes institutos que consideramos claves de la Reforma Constitucional, a saber, el Jefe de Gabinete de Ministros y los Decretos de Necesidad y Urgencia.

Además, volveremos a otros elementos incorporados por el constituyente, olvidados por el discurso hegemónico, como; la autonomía de la Ciudad de Buenos Aires y la elección directa de su Jefe de Gobierno; las autonomías municipales; la jerarquización constitucional de la Defensoría del Pueblo así como de los tratados internacionales y de integración latinoamericana; el reconocimiento de la identidad de los pueblos originarios; la Igualdad de género; la garantía de la gratuidad de la educación como responsabilidad indelegable del Estado, la autonomía y autarquía de las universidades nacionales; la Incorporación de un tercer senador que supone una representación más cabal de la ciudadanía de cada provincia y una defensa más franca de los intereses provinciales.

\section{Hacia el Pacto de Olivos}

\subsection{Consejo para la Consolidación de la Democracia}

El $1^{\circ}$ de diciembre de 1985, como mecanismo institucional facilitador de construcción de consensos, nace el Consejo para la Consoli- 
dación de la Democracia confirmado por Carlos Nino (jurista y filósofo), Oscar Albrieu (justicialista), José Antonio Allende (demócrata cristiano), Ismael Amit (Movimiento Federalista Pampeano), Leopoldo Bravo (bloquismo), Genaro Carrió (constitucionalista), Raúl Dellepiane (socialista), Guillermo Estévez Boero (socialista), René Favaloro (cardiólogo), Ricardo Flouret (militar), Enrique Nosiglia (radical), Julio H. Olivera (pedagogo), Emma Pérez Ferreira (físico-matemática), Oscar Puiggrós, Ángel F. Robledo (justicialista) Fernando Storni (sacerdotecatólico), Jorge A. Taiana (justicialista), Alfredo Vítolo (desarrollista), María Elena Walsh (artista) y Emilio Weinschelbaum (derechos humanos).

Resumidamente diremos que las conclusiones a las cuales arribó el Consejo para la Consolidación de la Democracia en el Dictamen presentado el 7 de octubre de 1986 se centraban en la necesidad de entrar en la transición a un sistema mixto que pudiera combinar elementos del Presidencialismo y del Parlamentarismo y que incluyeran los siguientes elementos:

- Descentralización política y nuevas formas de participación en la toma de decisiones y de control.

- Fortalecimiento del Federalismo

- Fortalecimiento de los municipios

- Incorporación de mecanismos de democracia semi-directa.

- Modernización del sistema de Administración de Justicia

- Durante esos años 1986 y 1987 la idea fue ampliamente analizada y discutida en el seno de los dos grandes partidos, como también en otras fuerzas políticas, económicas y sociales, así como en ámbitos académicos. ${ }^{3}$

\subsection{La Renovación Justicialista}

Desde la primera derrota del Partido Justicialista en elecciones libre, la vida política interna del Partido Justicialista experimentaba un proceso de intento de democratización, liderado por Antonio Cafiero y Menem, que prometía cambiar las reglas de juego de la política nacional abriendo paso a un escenario de posibles consensos.

3 ROSATTI, Horacio D. La reforma de la constitución explicada por miembros de la comisión de redacción, Ed. Rubinzal - Culzoni, 1994, p. 294. 
Teniendo como precedente los comicios de septiembre de 1987, que resultaron en un importante triunfo para el peronismo, cambiando así el mapa política y el rumbo de la reforma, en su doble carácter de Gobernador y Presidente del Partido Justicialista Cafiero suscribe el 14 de enero de 1988 con el Presidente de la Nación, un documento conjunto con las principales directrices de la reforma, la cual se estimó que podría realizarse conjuntamente con las elecciones presidenciales de 1989.

Sin embargo, ese año, la competencia electoral, encabezada por el Dr. Menen por hacerse con el mando del Justicialismo, sacó la reforma de la Constitución de la agenda política y puso el acento en la lucha interna por la candidatura presidencial entre este último y Cafiero que se hizo evidente tras el Congreso partidario de Tucumán.

En este contexto, y alejándose de la "Renovación", de la cual había tenido parte fundante, Menem comienza a acercarse a los ortodoxos, en particular a la "62" y al "grupo de los 15".

Finalmente, en las elecciones internas del 9 de julio de 1988 la fórmula Menem- Duhalde se impone frente con el 53,4\% de votos sobre el $45,8 \%$ de la fórmula encabezada por Cafiero, quien se opuso a que la Renovación se mantuviera como una línea interna del partido.

Rápidamente los sectores que antes se habían identificado con la Renovación, se encolumnaron tras la figura de Menem, dando fin a un movimiento que pretendía democratizar la vida interna del PJ.

El 14 de mayo de 1989 Menem se impone al radical Eduardo Angeloz con el 49,3\% de los votos en las elecciones presidenciales y el 8 de julio asume la Presidencia de la Nación.

\subsection{Las Negociaciones con Menem}

La necesidad de avanzar con una reforma constitucional reaparece en la escena pública el 23 de marzo de 1992, con un discurso del entonces Presidente Menem, en el que relanza la reforma constitucional, reivindicando la búsqueda del consenso a expresarse en un nuevo pacto que conjugue principios del constitucionalismo liberal con principios del constitucionalismo social.

En los documentos producidos por la comisión de Juristas creada a su efecto, se manifestaba la necesidad de una reforma constitucional que, a pesar de contemplar varias de las propuestas de 1988, impulsadas 
en conjunto por Cafiero y Alfonsín, tuviera un fin electoral muy claro: la conservación y el acrecentamiento del poder presidencial, esto es, la reelección de Menem.

El 7 de julio de 1993 se presentó el proyecto de reforma del bloque justicialista que recogía muchos puntos del Consejo para la Consolidación de la Democracia; jury de enjuiciamiento para los magistrados inferiores; elecciones presidenciales y senatoriales directas; disminución del término del mandato de los senadores; prolongación del período de sesiones; control legislativo sobre la vigencia del estado de sitio; simplificación del trámite de sanción de las leyes; sanción ficta; veto parcial; eliminación de la cláusula confesional; reducción del mandato a cuatro años; reelección presidencial; elección directa del intendente de la ciudad de Buenos Aires; convocatoria al Congreso en caso de intervención a una provincia; supresión del número de ministros; autarquía del Poder Judicial; autonomía política y económica de los municipios; integración regional de las provincias; preservación del medio ambiente; reconocimiento de los partidos políticos; formas de democracia semidirecta; sistema de enmiendas a un solo artículo; reconocimiento de competencias delegadas a los organismos internacionales de integración; hábeas corpus y amparo; acceso a la protección de la salud; defensa del usuario y el consumidor; promoción del acceso a la cultura, la ciencia, la investigación y la innovación tecnológica; regulación de los reglamentos de necesidad y urgencia; cláusula para el progreso; derecho a la información; auditoría general de la República; defensor del pueblo; Consejo de la Magistratura.

Además de estos puntos, en el proyecto se volcaba la pretensión del Justicialismo de avanzar con una reforma a la medida del neoconservadurismo que emanaba de la dirección política del gobierno menemista.

La presentación de este proyecto que asegurada la reforma del Estado, desembocó en una reunión el 4 de noviembre de 1993 entre Raúl Alfonsín, Mario Losada, titular del partido radical, Enrique Nosiglia, Eduardo Menem, Eduardo Bauza, Eduardo Duhalde y Luis Barrionuevo en la cual el primero propuso volver a los puntos planteados por el Consejo para la Consolidación de la Democracia.

De esa reunión surgió el documento llamado "Bases de Coincidencias" básicas, que abrió el camino para el Pacto de Olivos, firmado el 14 de noviembre de 1993 entre Menem y Alfonsín como referentes 
del PJ y de la UCR, refrendado a posteriori por los respectivos cuerpos orgánicos de ambos partidos.

El acuerdo político se profundizó en una segunda etapa conocida con el nombre de "Pacto de la Rosada" -firmado en la Casa de Gobierno el 13 de Diciembre de 1993 - que limitaba el llamamiento a la Convención Constituyente a una serie de temas para la modernización de ambas partes de nuestra Constitución, la dogmática y la orgánica, sin alterar el contenido de la primera.

Estos acuerdos fueron posteriormente puestos a consideración del Congreso de la Nación, que sancionó así la Ley № $24.309^{4}$, constituyendo la Convención Constituyente.

\subsection{Contenido del Pacto}

El Pacto de Olivos contemplaba las siguientes coincidencias básicas para impulsar un proyecto de reforma constitucional:

1. Consolidación del sistema democrático y perfeccione el equilibrio entre los poderes del Estado, por medio de:

- La atenuación del sistema presidencialista por medio de la incorporación de un Jefe de Gabinete o Ministro Coordinador, con responsabilidad frente al Presidente y al Congreso;

- La reducción del mandato del Presidente y Vicepresidente a cuatro años con reelección inmediata por un solo período, considerando el actual mandato presidencial como un primer período;

- Coincidentemente con el principio de libertad de culto se eliminará el requisito confesional para ser Presidente de la Nación;

- La elección directa de tres senadores, dos por la mayoría y uno por la minoría y la reducción de los mandatos de quienes resulten electos;

- La elección directa por doble vuelta del Presidente y Vicepresidente;

- La elección directa del Intendente de la Capital;

- La extensión de las sesiones ordinarias del Congreso;

4 Publicada en el Boletín Oficial el 31 de Diciembre de 1993. 
- Reglamentación de la facultad presidencial de dictar reglamentos de necesidad y urgencia.

- Reafirmación de que la intervención federal es competencia del Congreso Nacional.

2. Afiance la independencia de la justicia y fortalezca los órganos de control, de modo tal que:

- Modifique sustancialmente el modo de designación de los jueces y garantice la prevalencia de la idoneidad por encima de cualquier otro motivo de selección;

- Genere un procedimiento de remoción de los jueces ajeno a contingencias político-partidarias;

- Otorgue al órgano de control de la administración plena autonomía funcional en el ámbito del Poder Legislativo y periódica estabilidad a sus miembros, otorgando a la oposición su presidencia.

3. Rediseñe el régimen federal para favorecer el progreso y desarrollo económico de provincias y regiones.

4. Favorezca la integración latinoamericana y continental.

\subsection{Objetivos de la Reforma}

De los documentos y pactos analizados surge claramente que la Reforma de 1994 tuvo como uno de los objetivos claramente explicitados atenuar el presidencialismo, reafirmar la división de poderes y lograr un mayor protagonismo del Poder Legislativo.

Pero como hemos visto hasta aquí, estos objetivos se fueron configurando desde la recuperación de la democracia, pasando por el estudio del Consejo para la Consolidación de la Democracia, las negociaciones entre los dos partidos mayoritarios, la UCR y el PJ y los consensos a los que se logró arribar luego de varios años de debates.

Tal como fue expresado por el Constitucionalista Auyero, durante la Convención Nacional Constituyente "El miembro informante del justicialismo dijo que avanzamos hacia la atenuación del sistema presidencialista, mientras que el miembro informante del radicalismo dijo que avanzamos hacia un sistema semiparlamentario. Evidentemente, son dos cosas distintas. Los dos informaron el mismo despacho pero es que con la tradición política de ambas fuerzas es coherente lo que dijeron ya 
que el justicialismo siempre ha sido más presidencialista y el radicalismo más parlamentarista; de hecho, el Consejo para la Consolidación de la Democracia planteaba el parlamentarismo. Radicales y peronistas han conciliado un texto y yuxtapuesto sus ideas y salió un híbrido".

Tal como analizaremos más adelante, estas dos visiones diferentes, la del radicalismo y la del justicialismo, coherentes con las lógicas de concebir el poder de cada uno de estos partidos, tendrá una importante influencia en la puesta en práctica de la Constitución Reformada.

Más allá de estas divergencias, la Reforma "fue fruto de una voluntad tendiente a lograr, entre otros objetivos, atenuación del sistema presidencialista, el fortalecimiento del rol del Congreso y la mayor independencia del Poder Judicial.". 5

En esa dirección avanzó la mayoría de las fuerzas políticas en la Convención Nacional Constituyente. El constituyente Paixao, por ejemplo, manifestó que "ese conjunto de reformas significa asumir como hecho que la actual etapa histórica de la Argentina no es la etapa del hiperpresidencialismo al servicio de la organización nacional, sino la de una descentralización del poder que posibilite un avance armónico y por consenso de la mayor cantidad posible de integrantes de la sociedad política.”.

Resumiendo, los objetivos estructurales de la reforma iban en línea con la necesidad de atenuar el presidencialismo, lograr el real equilibrio entre los poderes del Estado, afianzar la independencia de la justicia y fortalecer los órganos de control, y rediseñar el régimen federal para favorecer el progreso y desarrollo económico de provincias y regiones.

\section{De la Teoría a la Práctica}

A los efectos de responder si los objetivos de los constituyentes se cumplieron o no y poder profundizar sobre los porqués, analizaremos algunos de los institutos implicados en la Reforma, a saber: la figura del Jefe de Gabinete de Ministros y el Régimen de los Decretos de Necesidad y Urgencia.

\subsection{El jefe de gabinete de ministros}

\subsubsection{La Teoría}

La figura del Jefe de Gabinete de Ministros "representó un compromiso ideológico entre las posiciones de los dos principales partidos ${ }^{5}$ Caso "Verrochi", Fallos, 322:1726 (1999). 
argentinos (el justicialismo y el radicalismo), y sintetizó varios de los fines perseguidos por la reforma constitucional.”(García Lema 1995).

El Consejo para la Consolidación de la Democracia proponía un "régimen presidencialista flexibilizado" o "mixto", por medio de la incorporación de un instituto novedoso en nuestro país, resultado de consensos políticas con una configuración casi sin antecedentes en el derecho comparado, esto es, la figura de un "jefe de gabinete" o "primer ministro", a quien se otorgarían las funciones de "Jefe de la Administración Pública”, que seria designado por el Presidente, pero que pudiera ser removido a través de moción de censura del Poder Legislativo.

Se planteaba también la posibilidad de que este "Primer Ministro" y los restantes miembros del gabinete pudieran ser diputados de la Nación, conservando sus bancas. Además, el Presidente tendría la facultad, propia de regímenes parlamentarios, de disolver la Cámara de Diputados para convocar a nuevas elecciones.

Al abrirse negociaciones entre el justicialismo y el radicalismo en 1993, con motivo del "Acuerdo de Olivos", el tema reaparece, a partir de la posición de los últimos, favorable a la existencia de un "primer ministro" que compartiera con el Presidente la función ejecutiva, mientras el justicialismo admitía sólo una "atenuación" del poder presidencial, a través del traslado de algunas funciones al "jefe de gabinete" (FLEITAS, 1995).

Las negociaciones que llevaron a la fórmula tal cual fue volcada en la Constitución Reformada, tuvieron varias etapas: se pasó del acuerdo por buscar "la atenuación del sistema presidencialista, mediante la incorporación de un jefe de gabinete o ministro coordinador con responsabilidad política frente al Presidente y al Congreso", tal como lo establecía el Pacto de Olivos, a la definición de las atribuciones constitucionales del Jefe de gabinete, con las características que luego se convirtieran en el actual art. 100 de la Constitución; sería nombrado y removido por el Poder Ejecutivo, tendría la responsabilidad política ante el Congreso, quien también podría removerlo mediante un voto de censura, en un documento interpartidario complementario del $1^{\circ}$ de diciembre de 1993.

El "Pacto de la Rosada" avanzó con la precisión de las facultades del Presidente como jefe supremo de la Nación, jefe de gobierno y responsable político de la administración general del país y se detallaron 
así las reformas que se realizarían al art. 86 de la Constitución en sus incs. $1^{\circ}, 10,13$ y 20 , puntos que no fueron objeto de modificaciones en la ley 24.309, sancionada y promulgada el 29 de diciembre de 1993 (Adla, LIV-A, 89), declarativa de la necesidad de la reforma.

Durante la Convención Constituyente, sin embargo, algunas precisiones fueron incorporadas a la figura que aquí nos convoca, a saber; entre las atribuciones del jefe de gabinete se reemplazó la expresión "tener a su cargo la administración general del país" por ejercer dicha administración; la facultad del jefe de gabinete de expedir actos y reglamentos, se condicionó al refrendo del ministro del ramo al cual el acto o reglamento se refiera; se estableció que la facultad de dicho jefe de resolver en acuerdo de gabinete por su propia decisión, en aquellas materias que por su importancia estime necesario, se cumplía "en el ámbito de su competencia" y se dispuso que el jefe de gabinete no podrá desempeñar simultáneamente otro ministerio.

La figura del Jefe de Gabinete de Ministros quedó finalmente establecida por la letra de la Constitución Reformada, que prevé las siguientes atribuciones y responsabilidades; envía al Congreso los proyectos de ley de ministerios y de presupuesto nacional, previo tratamiento en acuerdo de gabinete y aprobación del Poder Ejecutivo (Art. 100, inc. $6^{\circ}$ ), puede concurrir a las sesiones del Congreso y participar en sus debates, pero no votar (Art. 100, inc. $9^{\circ}$ ) - facultad que comparte con los ministros (Art. 106) -; debe presentar una memoria detallada del estado de la Nación en lo relativo a sus respectivos departamentos (Art. 100, inc. 10); debe producir los informes y explicaciones verbales o escritos que cualquiera de las Cámaras solicite al Ejecutivo (Art. 100, inc. 11), y tiene el deber de acudir al Congreso al menos una vez por mes, alternativamente a cada una de las Cámaras, para informar sobre la marcha del gobierno; pudiendo ser interpelado a los efectos del tratamiento de una moción de censura, y ser removido por el voto de la mayoría absoluta de los miembros de cada una de las Cámaras (Art. 101).

Otra responsabilidad, no menos importante, a cargo del Jede de Gabinete es la de presentar personalmente los decretos de necesidad y urgencia, dentro de los diez días de dictados, a la Comisión Bicameral Permanente, integrada por representantes de los diversos bloques de ambas cámaras, en proporción a su número (art. 99, inc. $3^{\circ}$ ). Sobre este punto profundizaremos especialmente más adelante. 
Como vemos, el articulado de la Reforma Constitucional convierte al Jefe de gabinete en un enlace institucional entre el Poder Ejecutivo y el Legislativo, haciéndolo responsable frente a éste, que lo puede remover mediante un voto de censura. Se pretendía crear un límite que pudiera no solo atenuar el presidencialismo argentino, sino también un "fusible" ante una posible crisis institucional.

Como expusiera Alfonsín (2004) en su Memoria Política, la figura del Jefe de Gabinete que se intentó plasmar en la Convención Constituyente, "flexibiliza el régimen político y contribuye a solucionar los problemas de gobernabilidad generados por el hiperpresidencialismo. Prevé que cuando existiera una situación de bloqueo entre el Presidente y el Congreso, el jefe de Gabinete con responsabilidad parlamentaria podría ser un puente a través del cual institucionalizar un gobierno de coalición.".

Se esperaba también que se abriera "la posibilidad de que la competencia política pierda su carácter de "juego de suma cero", ya que el incentivo a los acuerdos y coaliciones legislativas ofrece la posibilidad de una mayor participación a los partidos que no se encuentran en el ejercicio directo del gobierno. (...) Lo que nunca podrá hacer (el Presidente), con el nuevo diseño constitucional, es gobernar desde la excepcionalidad, atento a que cualquiera de sus dos institutos (decretos de necesidad y urgencia y legislación delegada) requieren la aprobación del Congreso, en la que la mayoría legislativa opositora de una de las Cámaras hará sentir su peso" (ALFONSÍN, 2004).

\subsubsection{La Práctica}

\section{Nombramiento}

Desde 1994 cada uno de los Jefes de Gabinete ha sido nombrado unilateralmente por el Presidente de turno, y siempre perteneció al mismo partido político que éste.

\section{Facultades}

La legislación que siguió a la reforma, bajo el discurso de la necesidad de mejorar la gobernabilidad, fue delegando facultades en el Jefe de Gabinete, que algunos gobiernos tomaron como atribuciones propias del Poder Ejecutivo, y no como facultades delegadas. 
En el año 2003, el art. 56 de la Ley № $25.725^{6}$, modificatoria de la ley 24.156, facultó al JGM a adecuar el Presupuesto General de la Nación, a los efectos de incorporar las partidas presupuestarias ejecutadas durante el período en que haya regido la prórroga prevista, sin exceder el total de créditos aprobado por la Ley de Presupuesto del año correspondiente.

En el 2006 por el art. $1^{\circ}$ de la Ley $\mathrm{N}^{\circ} 26.124^{7}$, se estableció que el JGM puede disponer las reestructuraciones presupuestarias dentro del total aprobado por cada ley de presupuesto, quedando comprendidas las modificaciones que involucren a gastos corrientes, gastos de capital, aplicaciones financieras y distribución de las finalidades. Además, se lo exceptúa del artículo 15 de la Ley $N^{\circ}$ 25.917, de Responsabilidad Fiscal, que impide aumentar el gasto corriente en detrimento del gasto de capital. Estos atributos se tratan de una delegación de facultades inconstitucional, al incumplir el Art. 76 de la Constitución que "prohíbe la delegación legislativa en el Poder Ejecutivo, salvo en materias determinadas de administración o de emergencia pública, con plazo fijado para su ejercicio y dentro de las bases de la delegación que el Congreso establezca.".

\section{Informes a las Cámaras del Congreso}

Salvo por los casos de Jorge Alberto Rodríguez y Rodolfo Terragno, los Jefes de Gabinete no han respetado el deber constitucional de acudir al Congreso al menos una vez por mes.

\begin{tabular}{|l|c|c|}
\hline \multicolumn{1}{|c|}{ JGM } & INFORMES A DIPUTADOS & INFORMES A SENADO \\
\hline EDUARDO BAUZÁ & 2 de 4 & $3 \mathrm{a} 4$ \\
\hline JORGE ALBERTO & $18 \mathrm{de} 18$ & 17 de 18 \\
\hline RODOLFO TERRAGNO & 3 de 3 & 4 de 3 \\
\hline CHRYSTIAN COLOMBO & 2 de 6 & 2 de 6 \\
\hline HUMBERTO SCHIAVONI & no & no \\
\hline LUIS LUSQUINOS & no & 1 de 1 \\
\hline JORGE CAPITANICH & 0 de 1 & 2 de 5 \\
\hline ALFREDO ATANASOF & 2 de 5 & 9 de 26 \\
\hline ALBERTO FERNANDEZ & 8 de 26 & 0 de 4 \\
\hline SERGIO MASSA & 1 de 4 & 3 de 10 \\
\hline ANIBAL FERNANDEZ & 2 de 10 & \\
\hline
\end{tabular}

\footnotetext{
6 B.O. 10/01/2003.

7 B.O. $8 / 8 / 2006$.
} 


\begin{tabular}{|l|c|c|}
\hline \multicolumn{1}{|c|}{ JGM } & INFORMES A DIPUTADOS & INFORMES A SENADO \\
\hline $\begin{array}{l}\text { JUAN MANUEL ABAL } \\
\text { MEDINA }\end{array}$ & $1 \mathrm{de} 8$ & $2 \mathrm{de} 8$ \\
\hline JORGE CAPITANICH & $4 \mathrm{de} 8$ & 4 de 7 \\
\hline ANIBAL FERNANDEZ & $0 \mathrm{de} 4$ & 0 de 5 \\
\hline
\end{tabular}

Fuente: Elaboración propia a partir de los informes de la Jefatura de Gabinete.

Este incumplimiento no hubiese sido posible si la responsabilidad política del Jefe de Gabinete fuera, efectivamente, ante el Legislativo. El JGM ha pasado a formar parte del PEN y, los informes, en vez de ser lazos entre ambos poderes, se han reducido al control por parte del Legislativo, y defensa de la gestión ejecutiva que ha asumido para sí el JGM.

\section{Remisión de Decretos al Congreso de la Nación}

Los datos recabados demuestran que mientras Alberto Fernández y Sergio Massa han cumplido casi al $100 \%$ con la obligación de remitir los Decretos de Necesidad y Urgencia, Decretos Delegados y Decretos de Promulgación Parcial de Leyes, en tiempo y forma, Anibal Fernandez y Juan Manuel Abal Medina, han descuidado este deber de manera preocupante. En el caso de Aníbal Fernández, éste no sólo presentó fuera de término 51 decretos de un total de 72 , sino que dejó uno sin remitir. Juan Abal Medina, por su parte, de un total de 28 decretos, presentó 10 fuera de término.

Jorge Capitanich presentó en tiempo y forma 20 decretos y uno sólo fuera de tiempo, mientras Anibal Fernandez, en su segundo mandato como Jefe de Gabinete, presentó correctamente 12 decretos y fuera de plazo 2.

\begin{tabular}{|l|c|c|c|}
\hline \multicolumn{1}{|c|}{ JGM } & $\begin{array}{c}\text { DNU, DPPL y DD } \\
\text { presentados en tiem- } \\
\text { po y forma }\end{array}$ & $\begin{array}{c}\text { DNU, DPPL y DD } \\
\text { no presentados en } \\
\text { tiempo y forma }\end{array}$ & $\begin{array}{c}\text { DNU, DPPL y DD } \\
\text { no remitidos }\end{array}$ \\
\hline ALBERTO FERNANDEZ & 60 & 1 & 0 \\
\hline SERGIO MASSA & 12 & 0 & 0 \\
\hline ANIBAL FERNANDEZ & 20 & 51 & 0 \\
\hline $\begin{array}{l}\text { JUAN MANUEL ABAL } \\
\text { MEDINA }\end{array}$ & 18 & 10 & 0 \\
\hline JORGE CAPITANICH & 20 & 1 & 0 \\
\hline ANIBAL FERNANDEZ & 12 & 2 & 1 \\
\hline
\end{tabular}

Fuente: Elaboración propia partir de datos disponibles en los sitios web del Senado y la

Cámara de Diputados de la Nación. 


\section{Remoción y Sanción}

No existen casos de mociones de censura ni se han aplicado hasta el día de hoy las sanciones correspondientes a ningún Jefe de Gabinete por incumplimiento de los deberes del funcionario público, establecidos por el Código Penal en sus art. 248 y 249.

\section{Algunas reflexiones}

Mucho se ha dicho y escrito sobre la puesta en práctica de esta figura. Existe un importante consenso sobre la poca efectividad de esta nueva figura en la atenuación del presidencialismo.

"El diseño institucional finalmente adoptado, se encuentra muy lejos del sistema " mixto" pensado por el Consejo para la Consolidación de la Democracia, toda vez que el carácter unipersonal y presidencialista se mantiene al ser el Presidente Jefe de Estado, de Gobierno, de las Fuerzas Armadas y responsable político de la administración del país (...) Carece de independencia frente al Presidente quien lo nombra, remueve y le confiere instrucciones, de tal modo que implica una relación jerárquica, por lo que no existe la dualidad de jefaturas y por ello no es posible caracterizar a nuestro sistema como "semipresidencialista"..No existe investidura parlamentaria ni voto de confianza al no poder el Congreso designarlo ni dar aprobación al designado por el Presidente.". ${ }^{8}$

Coincidiremos en la poca efectividad de la figura del Jefe de Gabinete en la atenuación del presidencialismo, pero iremos más allá. Tal como planteábamos al inicio de este trabajo, la puesta en práctica de estos institutos incorporados por la Reforma ha tenido efectos contrarios a los buscados por los constituyentes.

El espíritu de la creación del Jefe de Gabinete no solo ha quedado frustrado por la práctica y la reglamentación de esta figura, sino que además sufrió una contrareforma de fondo.

El Jefe de Gabinete no limita el presidencialismo, por el contrario hiperpresidencialisa nuestro sistema dado que através de la normativa se han acrecentado las competencias del Poder Ejecutivo.

La legislación que siguió a la reforma respecto de la figura que estamos analizando, no solo no respetó los objetivos constitucionales,

8 MUÑOZ, Ricardo Alberto. La Jefatura del Gabinete de Ministros: Ni Atenuación ni "Fusible". 
sino que, bajo el discurso de la necesidad de mejorar la gobernabilidad, fue delegando más y más facultadas en el Jefe de Gabinete, que algunos gobiernos terminaron por tomar como "atribuciones propias del Poder Ejecutivo en rol de ejecutores del presupuesto", y no como las facultades delegadas que son.

Aquí se hace necesario que hacer dos aclaraciones. En primer lugar, se ha roto la idea del Jefe de Gabinete como un "fusible" entre el Poder Ejecutivo y el Poder Legislativo, quedando totalmente encastrado dentro del primero y perdiendo así la responsabilidad hacia el segundo.

Esto se debe a varios motivos pero, principalmente, al hecho de que "mientras el Presidente pueda remover por su simple voluntad a este funcionario, las características de "fusible" institucional servirían nada más que para preservar al Presidente del desgaste natural que supone el ejercicio de sus funciones pero no se producirían modificaciones de fondo en el funcionamiento de las instituciones.". ${ }^{9}$

Por otro lado, la moción de censura, que representa el mayor poder del Legislativo a la hora de hacer responsable al Jefe de Gabinete, exige el voto de la mayoría absoluta de la totalidad de los miembros de cualquiera de las Cámaras, y para su remoción se precisa el voto de la mayoría absoluta de los miembros de cada una de las Cámaras, lo cual resulta por lo menos difícil, sino casi imposible, de lograr.

Ahora debemos hacer la segunda aclaración. Además de las facultades constitucionales que tiene el Jefe de Gabinete, las cuales ya hemos visto, se le han acumulado, por medio de la legislación, otras muy amplias que han despertado un grande debate.

Nos estamos refiriendo a los comúnmente conocidos como "Superpoderes" previstos por el art. 37 de la Ley 24.156 que establece que "el Jefe de Gabinete de Ministros puede disponer las reestructuraciones presupuestarias que considere necesarias dentro del total aprobado por cada ley de presupuesto, quedando comprendidas las modificaciones que involucren a gastos corrientes, gastos de capital, aplicaciones financieras y distribución de las finalidades. A tales fines, exceptúase al Jefe de Gabinete de Ministros de lo establecido en el artículo 15 de la Ley $\mathrm{N}^{\circ}$ 25.917."

9 Muñoz, Ricardo Alberto, obra citada. 
Afirmaremos aquí que la cuestión de los "superpoderes" se trata de una delegación de facultades encubierta e inconstitucional, por no cumplir con las condiciones planteadas en el Art. 76 que "prohíbe la delegación legislativa en el Poder Ejecutivo, salvo en materias determinadas de administración o de emergencia pública, con plazo fijado para su ejercicio y dentro de las bases de la delegación que el Congreso establezca.

La caducidad resultante del transcurso del plazo previsto en el párrafo anterior no importará revisión de las relaciones jurídicas nacidas al amparo de las normas dictadas en consecuencia de la delegación legislativa", y por disponer de una delegación de facultades de carácter permanente que algunos gobiernos han tratado de imponer como facultades propias del Poder Ejecutivo y hacer de lo extraordinario algo ordinario.

Como hemos analizado, el del Jefe de Gabinete pasó de ser la herramienta de atenuación del presidencialismo, como perseguía la Reforma del 94, a un instrumento de acumulación de facultades propias del Poder Legislativo en la esfera del Ejecutivo.

La contrareforma se hace clara en la figura aquí estudiada; no solo se ha logrado el límite al presidencialismo, sino que, mediante la legislación post reforma, se creó el marco jurídico necesario para el hiperpresidencialismo que se intentaba desterrar.

\section{Decretos de Necesidad Y Urgencia}

\subsection{La Teoría}

Nuestro país cuenta con una antigua tradición constitucional, ratificada por la jurisprudencia, que sostiene que el Presidente está facultado a dictar decretos legislativos fundados en la necesidad y la urgencia. Uno de los objetivos de la Reforma fue establecer una delimitación de estas facultades.

El espíritu del Constituyente fue plasmado en el artículo 99 que reza: "El Presidente de la Nación tiene las siguientes atribuciones: ... 3. Participa de la formación de las leyes con arreglo a la Constitución, las promulga y hace publicar. El Poder Ejecutivo no podrá en ningún caso bajo pena de nulidad absoluta e insanable, emitir disposiciones de carácter legislativo. Solamente cuando circunstancias excepciona- 
les hicieran imposible seguir los trámites ordinarios previstos por esta Constitución para la sanción de las leyes, y no se trate de normas que regulen materia penal, tributaria, electoral o el régimen de los partidos políticos, podrá dictar decretos por razones de necesidad y urgencia, los que serán decididos en acuerdo general de ministros que deberán refrendarlos, conjuntamente con el jefe de gabinete de ministros."

Del citado Artículo 99 inc. 3o de la Constitución Nacional surge un principio general y una excepción, la cual analizaremos a continuación:

Principio general: “... El Poder Ejecutivo no podrá en ningún caso bajo pena de nulidad absoluta e insanable, emitir disposiciones de carácter legislativo...”.

Excepción: "Solamente cuando circunstancias excepcionales hicieran imposible seguir los trámites ordinarios previstos por esta Constitución para la sanción de las leyes, y no se trate de normas que regulen materia penal, tributaria, electoral o el régimen de los partidos políticos, podrá dictar decretos por razones de necesidad y urgencia, los que serán decididos en acuerdo general de ministros que deberán refrendarlos conjuntamente con el jefe de gabinete de ministros".

La norma incluida por la Reforma nos habla de "estado de necesidad". Entendemos que se refiere a aquél caracterizado por un perfil fáctico (urgente necesidad) y por otro de carácter institucional (imposibilidad de recurrir a los trámites ordinarios para la sanción de las leyes).

En este sentido es clarificador el criterio de la Corte en el caso "Verrocchi" 10 que [...] "para que el Poder Ejecutivo pueda ejercer legítimamente facultades legislativas que, en principio, le son ajenas, es necesaria la concurrencia de alguna de estas dos circunstancias: 1) Que sea imposible dictar la ley mediante el trámite ordinario previsto por la Constitución, vale decir, que las cámaras del Congreso no puedan reunirse por circunstancias de fuerza mayor que lo impidan, como ocurriría en el caso de acciones bélicas o desastres naturales que impidiesen su reunión o el traslado de los legisladores a la Capital Federal; o 2) que la situación que requiere solución legislativa sea de una urgencia tal que deba ser solucionada inmediatamente, en un plazo incompatible con el que demanda el trámite normal de las leyes.'

${ }^{10}$ Fallos 322: 1726, considerando 9 párrafo 1

Resenha Eleitoral (Florianópolis), v. 20, n. 1, p. 39-73, jul. 2016 
No caben dudas que el "presupuesto habilitante" para el dictado de un decreto de necesidad y urgencia ha de ser la existencia de una situación de excepcionalidad, traducida en la imposibilidad de seguir los trámites ordinarios para la sanción de las leyes, con lo cual resulta forzoso concluir que la crisis política habilitante para el dictado de tales decretos ha de reflejarse y entenderse como una falta total de repuesta del Poder Legislativo ante una necesidad súbita e imperiosa de su intervención.

Por otra parte, será necesario que exista una "situación de grave riesgo social" que actúe como causa de justificación en sentido lato y que los "remedios" adoptados sean adecuados para atender a la misma, como que aquella situación haya hecho necesaria la creación de medidas súbitas. Por lo que no bastará una situación de crisis legislativa, sino que es preciso que esa crisis impida subsanar o atender con la inmediatez necesaria la situación de grave riesgo social, ante las circunstancias excepcionales que deben ser palmarias.

Recién cuando los indicadores sociales y de la realidad denotan la imperiosa necesidad de contar con un instrumento idóneo para paliar la situación (de "emergencia"), y siempre que no se invada materias vedadas, se darán las circunstancias habilitantes o la permisión constitucional, restando -lógicamente - el mesurado análisis de cada previsión contenida en el "decreto" para observar si el mentado "instrumento" legal aprueba o no el llamado "test de razonabilidad", como cualquier otro decreto ordinario del Poder Ejecutivo o ley sancionada por el Congreso.

Resumiendo, para que el presidente pueda hacer uso de esta atribución exclusiva y excepcional que posee para dictar DNU, deben reunirse primeramente los siguientes requisitos: 1) concurrencia de circunstancias excepcionales que hicieren imposible seguir los trámites ordinarios previstos para la sanción de las leyes, 2) que el objeto de la pretensión, la necesidad y la urgencia, no pueda satisfacerse por ley, y 3 ) que no se trate sobre las materias expresamente prohibidas por el texto constitucional.

\subsection{La Práctica}

El Congreso Nacional, luego de veinte años de producida la última reforma constitucional, ha dado cumplimiento formal a la previsión del Artículo 99 inc. $3^{\circ}$ de la Constitución Nacional (C.N.) sobre los decretos de necesidad y urgencia (DNU), al sancionar la "ley especial" № 
$26.122{ }^{11}$ que rige el trámite y el alcance de la intervención del Congreso y conformar la Comisión Bicameral Permanente de Trámite Legislativo, recaudos ambos exigidos por dicha enmienda para dar validez a este tipo de normas.

A continuación demostraremos cómo su reglamentación, Ley $\mathrm{N}^{\circ} 26.122$, no solo conduce a un juego de suma cero y un inefectivo control, sino que además contrareforma la letra constitucional, llevando al vaciamiento de nuestro sistema republicano y a la pérdida de significado del "lawmakingprocess" como expresión de la declinación institucional argentina.

Con este objetivo, analizaremos el régimen legal de los decretos de necesidad y urgencia.

Comenzaremos por decir que, respecto de la intervención de las cámaras del Congreso de la Nación y la Comisión Bicameral Permanente (C.B.P.), el artículo 99, inciso 3o C.N., en lo pertinente, dispone: “... El jefe de gabinete de ministros personalmente y dentro de los diez días someterá la medida a consideración de la Comisión Bicameral Permanente, cuya composición deberá respetar la proporción de las representaciones políticas de cada Cámara. Esta comisión elevará su despacho en un plazo de diez días al plenario de cada Cámara para su expreso tratamiento, el que de inmediato consideraran las Cámaras...."

El Artículo 100, incisos 12- y 13으. C.N., lo siguiente: “... Al jefe de gabinete de ministros, con responsabilidad política ante el Congreso de la Nación, le corresponde: ... 12. Refrendar los decretos que ejercen facultades delegadas por el Congreso, los que estarán sujetos al control de la Comisión Bicameral Permanente." "13. Refrendar conjuntamente con los demás Ministros los decretos de necesidad y urgencia y los decretos que promulgan parcialmente leyes. Someterá personalmente y dentro de los diez días de su sanción estos decretos a consideración de la Comisión Bicameral Permanente."

Respecto de la intervención de la C.B.P., el Artículo 2 de la ley No 26.122 establece: "La Comisión Bicameral Permanente prevista en los artículos 99, inciso 3, y 100, incisos 12 y 13 de la Constitución $\mathrm{Na}$ cional se rige por esta ley y las disposiciones de su reglamento interno;

11 B.O. del 28 de Julio de 2006. Cabe señalar que la comisión se constituyó efectivamente el 14 de Octubre de 2006.

Resenha Eleitoral (Florianópolis), v. 20, n. 1, p. 39-73, jul. 2016 
y tiene competencia para pronunciarse respecto de los decretos: a) de necesidad y urgencia; b) por delegación legislativa; y c) de promulgación parcial de leyes, dictados por el Poder Ejecutivo nacional en los términos de los artículos 99, inciso 3; 76; 80 y 100, incisos 12 y 13 de la Constitución Nacional.".

En esta línea, el Artículo 10 de la leycitada dispone además que: "La Comisión Bicameral Permanente debe expedirse acerca de la validez o invalidez del decreto y elevar el dictamen al plenario de cada Cámara para su expreso tratamiento. El dictamen debe pronunciarse expresamente sobre la adecuación del decreto a los requisitos formales y sustanciales establecidos constitucionalmente para su dictado. Para emitir dictamen, la Comisión Bicameral Permanente puede consultar a las comisiones permanentes competentes en función de la materia.".

Los siguientes artículos de la ley también refieren a las cámaras y la C. B. P., en lo pertinente, de la siguiente manera:

"Incumplimiento" "ARTICULO 18. - En caso de que el Jefe de Gabinete no remita en el plazo establecido a la Comisión Bicameral Permanente los decretos que reglamenta esta ley, dicha Comisión se abocará de oficio a su tratamiento. Para ello, el plazo de diez días hábiles para dictaminar, se contará a partir del vencimiento del término establecido para la presentación del Jefe de Gabinete.'

"Despacho de la Comisión Bicameral Permanente" "ARTICULO 19. - La Comisión Bicameral Permanente tiene un plazo de diez días hábiles contados desde la presentación efectuada por el Jefe de Gabinete, para expedirse acerca del decreto sometido a su consideración y elevar el dictamen al plenario de cada una de las Cámaras. El dictamen de la Comisión debe cumplir con los contenidos mínimos establecidos, según el decreto de que se trate, en los Capítulos I, II, III del presente Título."

"Tratamiento de oficio por las Cámaras" "ARTICULO 20. Vencido el plazo a que hace referencia el artículo anterior sin que la Comisión Bicameral Permanente haya elevado el correspondiente despacho, las Cámaras se abocarán al expreso e inmediato tratamiento del decreto de que se trate de conformidad con lo establecido en los artículos 99, inciso 3 y 82 de la Constitución Nacional." 
"Plenario" "ARTICULO 21. - Elevado por la Comisión el dictamen al plenario de ambas Cámaras, éstas deben darle inmediato y expreso tratamiento."

"Pronunciamiento" "ARTICULO 22. - Las Cámaras se pronuncian mediante sendas resoluciones. El rechazo o aprobación de los decretos deberá ser expreso conforme lo establecido en el artículo 82 de la Constitución Nacional." (...) "Cada Cámara comunicará a la otra su pronunciamiento de forma inmediata."

No caben dudas que el "presupuesto habilitante" para el dictado de un decreto de necesidad y urgencia ha de ser la existencia de una situación de excepcionalidad, traducida en la imposibilidad de seguir los trámites ordinarios para la sanción de las leyes, con lo cual resulta forzoso concluir que la crisis política habilitante para el dictado de tales decretos ha de reflejarse y entenderse como una falta total de repuesta del Poder Legislativo ante una necesidad súbita e imperiosa de su intervención.

Por otra parte, será necesario que exista una "situación de grave riesgo social" que actúe como causa de justificación en sentido lato y que los "remedios" adoptados sean adecuados para atender a la misma, como que aquella situación haya hecho necesaria la creación de medidas súbitas. Por lo que no bastará una situación de crisis legislativa, sino que es preciso que esa crisis impida subsanar o atender con la inmediatez necesaria la situación de grave riesgo social, ante las circunstancias excepcionales que deben ser palmarias. Recién cuando los indicadores sociales y de la realidad denotan la imperiosa necesidad de contar con un instrumento idóneo para paliar la situación (de "emergencia"), y siempre que no se invada materias vedadas, se darán las circunstancias habilitantes o la permisión constitucional, restando -lógicamente - el mesurado análisis de cada previsión contenida en el "decreto" para observar si el mentado "instrumento" legal aprueba o no el llamado "test de razonabilidad", como cualquier otro decreto ordinario del Poder Ejecutivo o ley sancionada por el Congreso. ${ }^{12}$

\footnotetext{
12 Así lo habíamos manifestado en nuestra ponencia ante el XVIII Encuentro Argentino de Profesores de Derecho Constitucional (Paraná, setiembre de 2007) y reiterado en nuestra participación sobre el mismo tema en el Encuentro Conjunto de la Asociación Argentina de Derecho Constitucional y la Asociación Argentina de Derecho Administrativo (Buenos Aires, abril de 2008).
}

Resenha Eleitoral (Florianópolis), v. 20, n. 1, p. 39-73, jul. 2016 
Respecto del rol que debe cumplir el Congreso en el tratamiento de un decreto de necesidad y urgencia (DNU) que llegare a su seno, es de someterlo a lo que en la doctrina se ha denominado "control político" del decreto.

Midón (2001) ${ }^{13}$ señala que verificar si un DNU satisface el test de razonabilidad es una operación lógica que para el operador de la Constitución (Poder Judicial y/o Congreso) debe principiar por el examen de la necesariedad del acto, o sea la comprobación objetiva de que concurre el hecho habilitante tipificado por la Ley Fundamental. Esto es, la existencia de necesidad, más la urgencia, más los acontecimientos que impiden la deliberación del Congreso.

Habrá dos aspectos que el Congreso no podrá soslayar conforme la consagración constitucional: a) la necesariedad de su intervención en la consideración de la norma de excepción, y b) la necesidad de que debe existir una manifestación expresa (de aprobación o rechazo) ya que el Artículo 82 de la Constitución Nacional y el Artículo 22 de la ley № 26.122 excluyen todo intento de considerar convalidado un DNU por el mero silencio.

Por último diremos que la ley № 26.122 (Artículos 22 y 26) obliga al Congreso a resolver dentro de las alternativas de lo ordenado: ACEPTACION O RECHAZO de la norma, impidiendo cualquier modificación del texto remitido. Textualmente el artículo 23 ordena: "Impedimento. ARTICULO 23.- Las Cámaras no pueden introducir enmiendas, agregados o supresiones al texto del Poder Ejecutivo, debiendo circunscribirse a la aceptación o rechazo de la norma mediante el voto de la mayoría absoluta de los miembros presentes."

La convalidación por la C.B.P. de los decretos sometidos a su examen importa convalidar un avasallamiento a las facultades que el constituyente de 1994 otorgó al Poder Legislativo. Recordemos que en el procedimiento de sanción legislativa nos encontramos frente a un acto complejo que requiere de la voluntad de dos órganos: el Poder Ejecutivo que lo dicta y el Poder Legislativo que tiene a su cargo el examen y control del decreto. A este último, como órgano de contralor, le compete pronunciarse sobre la concurrencia de los extremos que habilitan

13 MIDON, Mario A. R. "Decretos de Necesidad y Urgencia en la Constitución Nacional y los ordenamientos provinciales”. La Ley. 2001. Bs. As, p. 120. 
el ejercicio de esta facultad excepcional del Poder Ejecutivo: mérito, oportunidad y conveniencia de su contenido, y es quien ratificará o no la normativa dictada.

Para que el dictado de este tipo de normas sea considerado constitucionalmente válido, es menester que exista una situación de grave riesgo social, debido a que nuestra Carta Magna, no habilita a elegir discrecionalmente entre el dictado de un DNU o una ley.

El apartamiento de estos principios básicos del sistema republicano son un síntoma elocuente por sí mismo del proceso de contrareforma que vivimos, y que nos exige un replanteo sin atenuantes de ningún tipo.

A más de cinco años de funcionamiento de la C.B.P. el balance no resulta para nada positivo. Es evidente que el control no ha sido efectivo, por el cual - más allá de consideraciones propias de la sociología constitucional- consideramos oportuno una reforma parcial a la Ley № 26.122 .

Como venimos viendo, la Comisión, desde su puesta en funcionamiento, ha sufrido ciertos avatares producto de la falta de claridad conceptual en ciertos artículos de la ley 26.122. Detallaremos a continuación los problemas que consideramos más preocupantes de esta ley y creemos deberían ser modificados para un control efectivos por parte de la Comisión:

- La intervención del Congreso fue establecida como una mera apariencia de controlador.

- Es necesario limitar la potestad excepcional del poder Ejecutivo de emitir normas de naturaleza legislativa, poniendo fin a una práctica que pretende convertir lo extraordinario en ordinario.

- Se debería eliminar la sanción ficta ya que El silencio del Congreso no puede tener efecto convalidatorio si se espera que el Legislativo asuma su responsabilidad y se termine con el permisivismo constitucional del que sufre nuestro sistema.

- Se debería poner la Presidencia en manos de la oposición para otorgar a la Comisión un impulso distinto y forjar la búsqueda del consenso democrático. 
- En caso de falta de remisión del decreto por el Jefe de Gabinete de Ministros el decreto debería ser nulo de nulidad absoluta e insanable, y el Jefe de Gabinete debería incurrir en responsabilidad política pasible de la sanción de censura de acuerdo a lo dispuesto por el Artículo 101 de la Constitución Nacional.

\subsection{Los Presidentes y los Decretos de Necesidad y Urgencia}

A continuación, se detalla la cantidad de Decretos de Necesidad y Urgencia Dictados por los presidentes argentinos, a partir de 1995.

\begin{tabular}{|c|c|c|}
\hline Presidencia & Año & $\begin{array}{l}\text { Decretos de Necesidad y } \\
\text { Urgencia }\end{array}$ \\
\hline \multirow[t]{6}{*}{ Menem } & 1995 & 8 \\
\hline & 1996 & 11 \\
\hline & 1997 & 27 \\
\hline & 1998 & 26 \\
\hline & 1999 & 41 \\
\hline & Total Presidencia Menem & 113 \\
\hline \multirow[t]{4}{*}{ De La Rua } & 1999 & 8 \\
\hline & 2000 & 26 \\
\hline & 2001 & 30 \\
\hline & Total Presidencia De La Rua & 64 \\
\hline Rodriguez Saa & 2001 & 5 \\
\hline \multirow[t]{3}{*}{ Duhalde } & 2002 & 109 \\
\hline & 2003 & 43 \\
\hline & Total Presidencia de Duhalde & 152 \\
\hline \multirow[t]{6}{*}{ Nestor Kirchner } & 2003 & 48 \\
\hline & 2004 & 63 \\
\hline & 2005 & 46 \\
\hline & 2006 & 59 \\
\hline & 2007 & 20 \\
\hline & $\begin{array}{l}\text { Total Presidencia Nestor } \\
\text { Kirchner }\end{array}$ & 236 \\
\hline
\end{tabular}




\begin{tabular}{|c|c|c|}
\hline Presidencia & Año & $\begin{array}{l}\text { Decretos de Necesidad y } \\
\text { Urgencia }\end{array}$ \\
\hline \multirow{5}{*}{$\begin{array}{l}\text { Cristina Kirchner } \\
1^{0} \text { mandato }\end{array}$} & 2008 & 3 \\
\hline & 2009 & 10 \\
\hline & 2010 & 10 \\
\hline & 2011 & 11 \\
\hline & $\begin{array}{l}\text { Total Presidencia Cristina } \\
\text { Kirchner } 1^{\circ} \text { mandato }\end{array}$ & 34 \\
\hline \multirow{5}{*}{$\begin{array}{l}\text { Cristina Kirchner } \\
2^{\circ} \text { mandato }\end{array}$} & 2012 & 11 \\
\hline & 2013 & 12 \\
\hline & 2014 & 12 \\
\hline & 2015 & 13 \\
\hline & $\begin{array}{l}\text { Total Presidencia Cristina } \\
\text { Kirchner } 2^{\circ} \text { mandato }\end{array}$ & 48 \\
\hline \multicolumn{2}{|c|}{ Total Cristina Kirchner } & 82 \\
\hline \multicolumn{2}{|l|}{ Total desde 1995} & 652 \\
\hline
\end{tabular}

Fuente: Elaboración propia partir de datos extraídos de la Comisión Bicameral de Trámite Legislativo, los sitios web del Senado y la Cámara de Diputados de la Nación.

Como se desprende del cuadro anterior, la regulación de los Decretos de Necesidad y Urgencia en el texto constitucional, y su posterior reglamentación por la Ley 26.122, no ha funcionado como efecto disuasivo que pudiera disminuir el dictado de este tipo de norma desde la Presidencia de la Nación.

\section{Esbozando Propuestas}

Hemos visto a lo largo de este trabajo que las dos visiones divergentes de democracia, que se sostiene existen en la argentina, han tenido un peso fundamental en este proceso dado que, tal como advirtiera Nohlen (2007), "parece que la mentalidad tradicional incide más en los resultados de tal reforma que las reformas mismas en el cambio de mentalidad.".

Sostenemos, a su vez que "una teoría de la democracia (de la democracia a secas) debe incluir también, y en un lugar muy central diversos aspectos de teoría del derecho, en medida que el sistema legal promulga y sustenta fundamentalmente características de la democracia" (O’DONNEL, 2007). 
En este trabajo se pretendió analizar el control constitucional y la figura del jefe de gabinete de ministros, en la convicción de que estas dos instituciones tienen un peso fundamental a la hora de intentar retomar el camino representativo que primó en épocas de la reforma y revertir la trayectoria delegativa en aras de construir una cultura política democrática (NOHLEN, 2007)

Respecto a la figura del Jefe de Gabinete de Ministros sostenemos la necesidad de terminar con la designación y remoción unilateral del mismo por parte del Presidente rompiendo la relación jerárquica existente, exigiendo el acuerdo del Senado para su designación.

Por otro lado, también se debe revisar la moción de censura, que representa el mayor poder del Legislativo a la hora de hacer responsable al Jefe de Gabinete, exige el voto de la mayoría absoluta de la totalidad de los miembros de cualquiera de las Cámaras, y el voto de la mayoría absoluta de los miembros de cada Cámara para su remoción, lo cual resulta casi imposible de lograr.

Para ello, se propone avanzar hacia una moción de censura por medio de los dos tercios de los presente de una de las Cámaras.

Se propone también terminar con las facultades delegadas en el Jefe de Gabinete, principalmente las establecidas en el Art. 37 de la Ley 24.156 de Administración Financiera, reservando al Congreso Nacional las decisiones que afecten el monto total del presupuesto y el monto del endeudamiento previsto, así como los cambios que impliquen incrementar los gastos corrientes en detrimento de los gastos de capital o de las aplicaciones financieras, y los que impliquen un cambio en la distribución de las finalidades.

Por último, debe ser revisado, a nuestro entender, el régimen legal de los decretos de necesidad y urgencia, de delegación legislativa y de promulgación parcial de leyes establecida por la Ley 26.122, dado que la intervención del Congreso fue establecida como una mera apariencia de controlador, como cuestión secundaria al no fijar un plazo para que éste se exprese.

Se plantea aquí que es necesario no sólo dar un valor efectivo y verdadero al control del Congreso, sino que, además, es de vital importancia que la responsabilidad funcional, tanto del Ejecutivo como del 
Legislativo, quede clara para que cada poder sepa hasta donde llega la tolerancia institucional.

Consideramos importante darle un cauce limitado a la potestad excepcional del poder Ejecutivo de emitir normas de naturaleza legislativa, poniendo fin a una práctica que pretende convertir lo extraordinario en ordinario.

Para el caso de falta de remisión por el Jefe de Gabinete de Ministros, creemos inminente establecer que carecerá de todo valor y eficacia jurídica, equivalente al rechazo del mismo, el decreto que no fuere remitido a la Comisión Bicameral Permanente para su consideración dentro del plazo establecido, y que en caso de incumplimiento por parte del Jefe de Gabinete la Comisión podrá abocarse de oficio al tratamiento de los decretos previstos en esta ley.

Por otro lado, el Jefe de Gabinete debería incurrir en responsabilidad política pasible de la sanción de censura de acuerdo a lo dispuesto por el Artículo 101 de la Constitución Nacional.

Además sostenemos la urgencia de eliminar la sanción ficta ya que "el silencio, en la práctica, produce efectos y por lo tanto se convierte en sanción ficta, o, más precisamente, en ratificación ficta, que es una variable de aquella aplicada a supuestos especiales en los cuales la voluntad legislativa deberá pronunciarse sobre el todo o nada" (CAYUSO 2006). El silencio del Congreso no puede tener efecto convalidatorio si se espera que el Legislativo asuma su responsabilidad y se termine con el permisivismo constitucional del que sufre nuestro sistema.

La última reforma que proponemos es la modificación del artículo 5o de la ley, con el fin de que el Presidente de la Comisión sea designado a propuesta del bloque político opositor con mayor número de legisladores en el Congreso.

\section{Bibliografía}

ALFONSÍn, Raul. Memoria Política", Fondo de Cultura, Bs. As., 2004.

ALTAVILLA, Cristian. "Coordinación y conflicto en las relaciones intergubernamentales. Los pactos fiscales de la década del '90", X Congreso de la SAAP, Córdoba, 2011. 
BELARDINELLI, Pablo - Corti, Horacio G. "Funciones financieras del Jefe de Gabinete de Ministros" (Teorías, dilemas, interpretaciones) LA LEY, Bs. As., 1996.

BELAÚNDE, Domingo García. El Control de Constitucionalidad de las Leyes, en El Derecho, 156:793.

BIDART CAMPOS, Germán. EI Derecho de la Constitución y su Fuerza Normativa, Buenos Aires, Ediar, 1995.

\section{. Tratado Elemental de Derecho Constitucional}

Argentino, Tomo II, Buenos Aires, Ediar.

CASSAGNE, Juan Carlos. "En torno al Jefe de Gabinete". LA LEY, Bs As 1994.

CAYUSO, Susana. "La delegación legislativa, los decretos de necesidad y urgencia y la promulgación parcial. Control político real o aparente", LA LEY, Bs. As., 2006.

CONSTITUCIÓN DE LA NACIÓN ARGENTINA.

DALLA VIA, Alberto Ricardo. "El imperio de la ley y su efectividad" en Gobernabilidad y constitucionalismo en América Latina", Diego Valadés Editor. UNAM, 2005.

DE RIZ, Liliana; ADROGUÉ, Gerardo. "Democracia y Elecciones en la Argentina 1983-1989”. Documento CEDES № 52, Bs. As., 1990.

DICTAMEN DEL CONSEJO PARA LA CONSOLIDACIÓN DE LA DEMOCRACIA, Eudeba, Bs. As., 1986.

FANELLI EVANS, Guillermo E. "El Jefe de Gabinete y demás Ministros del Poder Ejecutivo en la Constitución Nacional”, LA LEY 1994-E, Bs. As., 1994.

FLEITAS ORTIZ DE ROZAS, Abel. "El jefe de gabinete de ministros: perfiles e interrogantes", LA LEY 1995-C, Bs. As., 1995.

FROMONT, Michel., La Justice Constitutionnelledans le Monde,París, Dalloz, 1996.

GALLARDO, Roberto Andrés y López, Mario Justo (h). "El Jefe de Gabinete en la Constitución Nacional Reformada", El Derecho, t. 161, Bs. As., 1994 GAMBINI, Hugo. "Aquel otro juicio a la Corte”, en La Nación, del 17 de marzo de 2002. 
GARCÍA LEMA, Alberto M. "La jefatura de gabinete de ministros en el proyecto de ley de ministerios", LA LEY 1995-E, Bs. As., 1995.

GIBSON, Edward; CALVO, Ernesto. "Federalismo y Sobrerrepresentación: la dimensión territorial de la reforma económica en Argentina", en Calvo E. y Abal Medina, J. M. (h) (eds), El Federalismo Electoral Argentino. Sobrerrepresentación, reforma política y gobierno dividido en la Argentina, INAP - Eudeba, Bs. As., 2001.

GROSSI, María; GRITTI, Roberto. "Los partidos frente a una democracia difícil. La evolución del sistema partidario en la Argentina", Crítica y Utopía N_18, FUCADE, Bs. As., 1989.

HARO, Ricardo. "El Control de Constitucionalidad y el Rol Paradigmático de las Cortes y Tribunales Constitucionales" en Derecho Constitucional y Administrativo II, dirigido por Carello, Luis, Córdoba, Juris, 2000.

KVATERNIK, Eugenio. "Crisis sin salvataje. La crisis político-militar de 1961-1963”, Buenos Aires, Ediciones Universidad del Salvador, 1994.

LEGAZ LACAMBRA. Teoría General del Estado, trad. de México, Fondo de Cultura Económica, 1948.

LEY 26.122 publicada en el boletín oficial del 28 de julio de 2006.

LEY 24.156 publicada en el boletín oficial el 15 de diciembre de 1992 y modificaciones.

LEY 25.917 publicada en el boletín oficial el 25 de agosto del 2004 y modificaciones.

LES 24.309 publicada en el boletín oficial el 31 de diciembre de 1993.

LILLJEDAHL, Matilde. "Un camino paralelo a la coparticipaciónfederal: las transferencias del Estado Nacional”, X Congreso de la SAAP, Córdoba, 2011.

LLANOS, Mariana; MUSTAPIC, Ana María. "El control parlamentario en Alemania, Argentina y Brasil”. HomoSapiens Ediciones. Rosario, Santa Fe, 2006.

LOZANO, Luis Francisco. "El Jefe de Gabinete" LA LEY 1995-D, Bs. As., 1995.

MAINWARING S. Y Shugart M. S. (compiladores). Presidencialismo y democracia en América Latina, Paidós, Bs.As., lra. Edición, 2002.

MC ADAM, Andrew; SUKUP, Viktor. "RaulAlfonsin- La Democracia a Pesar de Todo”. Corregidor. Bs. As., 2009. 
MECLE, Elina; GUTERMAN, Dalia. "Vetos totales, parciales, insistencias y promulgación parcial", X Congreso de la SAAP, Córdoba, 2011.

MIDON, Mario A. R. Decretos de Necesidad y Urgencia en la Constitución Nacional y los ordenamientos provinciales. LA LEY. Bs. As., 2001.

MUÑOZ, Ricardo Alberto. La Jefatura del Gabinete de Ministros: Ni Atenuación ni "Fusible", Boletín Ftad. de Cs Económicas, Universidad Nac. de Río Cuarto, 2010.

OLLIER, María Matilde. La institucionalización democrática en el callejón: La inestabilidad presidencial en Argentina, Ed. Universidad de Salamanca América Latina Hoy, 2008.

O’DONNELL, Guillermo. Un juego imposible, Instituto Torcuato Di Tella. Centro de Investigaciones en Administración Pública. Documento de trabajo, Bs. As., 1972.

O'DONNELL, Guillermo. Delegative Democracy, Journal of Democracy, Vol. 5, No. 1, National Endowment for Democracy and The Johns Hopkins University Press, January 1994: 55-69, 1994.

O’DONNELL, Guillermo. La democratización y sus límites después de la tercera ola. Otra Institucionalización. KellogInstitute-University of Notre Dame, 1996.

O’DONNELL, Guillermo. Disonancias, Prometeo, Ciudad Autónoma de Buenos Aires, 2007.

PACTET, Pierre. Institutions Politiques. DroitConstitutionnel, París, Colin, 1997.

PAIXAO, Enrique. El Jefe de Gabinete de Ministros, en Rosatti, Horacio y otros, La Reforma de la Constitución, Rubinzal-Culzoni Editores, Santa Fe, 1994.

PEREZHUALDE, Alejandro. Decretos de Necesidad y Urgencia: su ley especial. Derecho Constitucional de la Reforma de 1994 -II-. Ed. Depalma Bs. As., 1995.

PEREZLIÑAN, Anibal. Pugna de poderes y crisis de gobernabilidad: ¿Hacia un nuevo presidencialismo?, en Latin American ReserchReview, 38 (3), 2003.

PERSELLO, Ana Virginia. Historia del Radicalismo. Edhasa. Bs. As., 2007. RASPI, Arturo Emilio. La jefatura de la administración general del país en la Constitución LA LEY, Bs. As., 1996. 
REGNIER, Pablo. De la boina blanca al sushi. Análisis del Partido Radical, 1890 - 2001. Distral. Bs. As., 2006.

ROLANDO TAMAYO Y SALMORÁN. La Garantía jurisdiccional de la Constitución (La Justicia Constitucional), trad. de, México, UNAM, 2001. ROSATTI, Horacio D. La reforma de la constitución explicada por miembros de la comisión de redacción, Ed. Rubinzal - Culzoni, Bs. As., 1994. SERRAFERO, Mario. Una reflexión a propósito del Jefe de Gabinete y la censura parlamentaria, El Derecho, t. 159, Bs. As.. 1994.

SANTIAGO ALFONSO $(\mathrm{H})$ Y THURY CORNEJO VALENTÍN. Tratado sobre la delegación legislativa. Editorial Ábaco de Rodolfo Depalma, Bs. As., 2003.

SEGUNDO DICTAMEN DEL CONSEJO PARA LA CONSOLIDACIÓN DE LA DEMOCRACIA. Consejo para la Consolidación de la Democracia. EUDEBA, Bs. As. 1987.

SPOTA, Alberto Antonio. Lo político, lo jurídico, el derecho y el poder constituyente, Buenos Aires, Plus Ultra, 1972.

¿Quién debe ejercer el control de constitucionalidad en Argentina? en Defensa de la Constitución. Obra colectiva en homenaje al Dr. Germán J. Bidart Campos. Editorial Ediar. Buenos Aires, ago. 2003.

Marcelo Alberto López Alfonsín - Professor de Derecho constitucional Universidad de Buenos Aires - UBA - mlopezalfonsin@yahoo.com.ar.

Ariela Schnitmann - Universidad de Buenos Aires, Argentina. 